\title{
Socioeconomic associations of improved maternal, neonatal, and perinatal survival in Qatar
}

This article was published in the following Dove Press journal:

International Journal of Women's Health

15 September 2010

Number of times this article has been viewed

\author{
Sajjad Rahman ${ }^{1,2}$ \\ Khalil Salameh' \\ Abdulbari Bener 1,3 \\ Walid El Ansari ${ }^{4}$ \\ 'Women's Hospital, Hamad \\ Medical Corporation, Doha, Qatar; \\ ${ }^{2}$ Department of Clinical Pediatrics, \\ Weill Cornell Medical College, Doha, \\ Qatar; ${ }^{3}$ Department of Evidence for \\ Population Health Unit, School of \\ Epidemiology and Health Sciences, \\ University of Manchester, Manchester \\ UK; ${ }^{4}$ Faculty of Applied Sciences, \\ University of Gloucestershire, \\ Gloucester, UK
}

\begin{abstract}
This retrospective study analyzed the temporal association between socioeconomic development indices and improved maternal, neonatal, and perinatal survival in the State of Qatar over a period of 35 years (1974-2008). We explored the association between reduction in poverty, improvement in maternal education, and perinatal health care on the one hand, and increased maternal, neonatal, and perinatal survival on the other hand. Yearly mortality data was ascertained from the perinatal and neonatal mortality registers of the Women's Hospital and the national database in the Department of Preventive Medicine at Hamad Medical Corporation in Doha. A total of 323,014 births were recorded during the study period. During these 35 years, there was a remarkable decline $(P<0.001)$ in Qatar's neonatal mortality rate from $26.27 / 1000$ in 1974 to $4.4 / 1000$ in 2008 and in the perinatal mortality rate from $44.4 / 1000$ in 1974 to $10.58 / 1000$ in 2008. Qatar's maternal mortality rate remained zero during 1993, 1995, and then in 1998-2000. The maternal mortality rate was $11.6 / 100,000$ in 2008 . For the rest of the years it has been approximately 10/100,000. Across the study period, the reduction in poverty, increase in maternal education, and improved perinatal health care were temporally associated with a significant improvement in maternal, neonatal, and perinatal survival. The total annual births increased five-fold during the study period, with no negative impact on survival rates. Neonatal mortality rates in Qatar have reached a plateau since 2005. We also conducted a substudy to assess the association between improvements in survival rates in relation to health care investment. For this purpose, we divided the study period into two eras, ie, era A (1974-1993) during which major health care investment was in community-based, low-cost interventions, and era B (1994-2008) during which the major health care investment was in high-technology institutional interventions. Although from 1974-1993 (era A) the per capita health expenditure increased by only 19\% as compared with a 137\% increase in 1994-2008 (era B). The decline in neonatal and perinatal mortality rates was three times steeper during era $\mathrm{A}$ than in era $\mathrm{B}$. The decline in neonatal and perinatal mortality rates was also significant $(P<0.001)$ when analyzed separately for era $\mathrm{A}$ and era $\mathrm{B}$. We concluded that across the 35 -year period covered by our study, the reduction in poverty, increased maternal education, and improved perinatal health care were temporally associated with improved maternal, neonatal, and perinatal survival in the State of Qatar. From the subanalysis of era A and era B, we concluded that low-cost, community-based interventions, on the background of socioeconomic development, have a stronger impact on maternal, neonatal, and perinatal survival as compared with high-cost institutional interventions.
\end{abstract}

Keywords: maternal, neonatal, perinatal, mortality rate, Qatar, health care costs

\section{Introduction}

The global disparity in maternal and neonatal survival ${ }^{1-11}$ remains a very big challenge for international perinatal health care planners. Worldwide, 0.536 million mothers 
and four million newborn babies (0-28 days of life) die every year. Ninety-nine percent of these global maternal and neonatal deaths occur in developing countries ${ }^{8}$ which are striving to achieve the millennium development goals (MDGs) of a two-third reduction in the deaths of children under five years of age and a three-quarter reduction in maternal deaths. ${ }^{9}$ The MDGs are the global targets set by the Millennium Summit of the United Nations held in September 2000. The world leaders attending the summit agreed that the targets must be achieved by 2015 . However, the midpoint assessment of MDG achievement, published by the World Health Organization (WHO) in 2007, has shown that the results are uneven, ${ }^{9}$ which is an unfortunate but not unexpected outcome. According to the WHO midterm report, a number of countries have done extremely well. ${ }^{9}$ This includes the six countries which constitute the Gulf Cooperation Council, ie, the United Arab Emirates, Bahrain, Qatar, Oman, Kuwait, and Saudi Arabia. In May 2010, The Lancet published a 28-year review (1980-2008) of maternal mortality in 181 countries $^{10}$ and a 40 -year review (1970-2010) of neonatal, postneonatal, childhood, and under-five mortality in 187 countries. ${ }^{11}$ These excellent reviews have shown that Qatar and the United Arab Emirates have achieved their maternal and childhood mortality rates, which are comparable with those in most of the developed world countries. ${ }^{10,11}$ The Arabian Gulf countries have achieved this excellent improvement in their maternal, neonatal, and perinatal health care indicators during the last two decades. ${ }^{1-3,9-19}$ This progress is the result of exponential socioeconomic development and investment in health care, education, and social infrastructure in these states, which started in the 1980s. ${ }^{17,18}$ Among the Gulf Cooperation Council countries, the State of Qatar is exceptional in not only achieving the highest gross domestic product per capita in the world, but also in achieving most of its MDGs by 2007. ${ }^{19}$ According to the International Monetary Fund, Qatar's gross domestic product per capita was $\$\left(\right.$ US 86,008 in 2008 and $\$ 87,716$ in $2009 .{ }^{20}$ The State of Qatar has a strong political commitment to its development, documented in Qatar's National Vision, announced in July 2008 by His Highness, the Emir of Qatar. ${ }^{21}$ Qatar's National Vision aims to transform Qatar into an advanced country by 2030 through human, economic, social, and environmental development. ${ }^{21}$ Qatar ranks very high in its social, educational, cultural, and equity of health care system, ${ }^{22,23}$ with the result that its current maternal, neonatal, and perinatal mortality rates are comparable with those of most of the developed countries (Figure 1). ${ }^{10,11,24}$

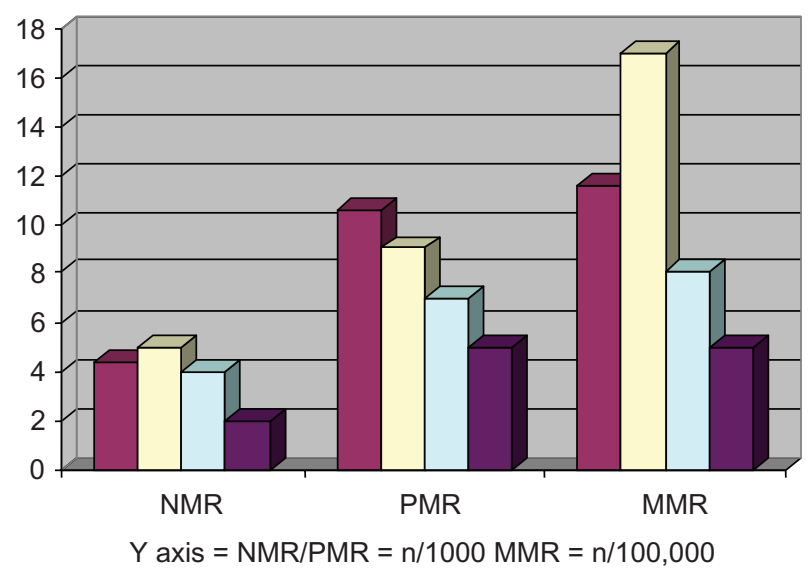

QATAR $\square$ USA $\square$ UK $\square$ Sweden

Figure I Comparison of Qatar's 2008 NMR, PMR and MMR with some of the developed world countries.

Abbreviations: MMR, maternity mortality ratio; NMR, neonatal mortality ratio; PMR, perinatal mortality ratio

The perinatal health planner's dilemma of where and how to invest in maternal, neonatal, and perinatal health care in the developing countries remains unresolved, ${ }^{25}$ with the main reasons being restricted resources and lack of political commitment. Recent studies have shown that the vast majority of global maternal and neonatal deaths are preventable through simple, low-cost, and effective community-based interventions backed up by socioeconomic development, a vibrant health system, and strong political commitment. ${ }^{25-28}$ The improvement in maternal, neonatal, and perinatal survival in the State of Qatar over the last 35 years (Figure 2) provides an excellent model to study this notion. In this study, we have used Qatar's data to analyze the association of socioeconomic development indicators with maternal, neonatal, and perinatal survival. Our analysis also provides an overview of how and where to invest in perinatal health care to get maximum survival rates in a resource-restricted environment. Our study, with the most longitudinal data for the Arabian Gulf region, provides useful information for determining the priorities for investment in maternal and neonatal health care in developing and underdeveloped countries.

\section{Subjects and methods}

Our study was retrospective, analytic, and descriptive, covering a period of 35 years (1974-2008). The study was approved by the Institutional Research Ethics Committee of the Hamad Medical Corporation, the largest state-owned health care provider in the State of Qatar. Hamad Medical Corporation also serves as a teaching hospital for the students of Weill Cornell Medical College in Qatar, which is a subsidiary of Weill Cornell University in New York. Hamad Medical 


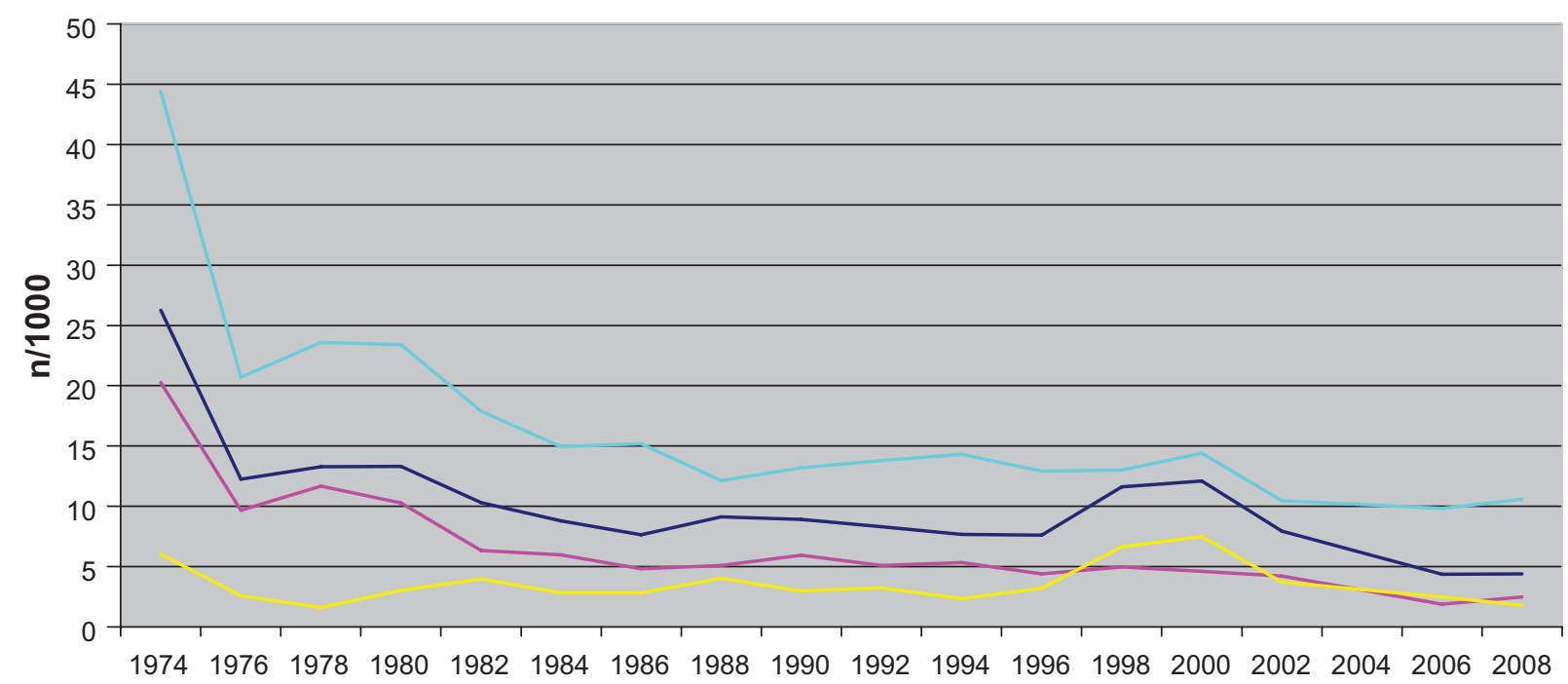

- NMR —ENMR LNMR - PMR

Figure 2 Biennial trends of NMR, ENMR, LNMR and PMR in Qatar from 1974 to 2008.

Abbreviations: ENMR, early neonatal mortality ratio; LNMR, late neonatal mortality ratio; NMR, neonatal mortality ratio; PMR, perinatal mortality ratio

Corporation and its Women's Hospital are accredited by the United States Joint Commission International for the standard and quality of health care they provide. The Women's Hospital is the only tertiary care maternity and neonatal center in Qatar. The state has a number of secondary care centers both in the public and private sector. The major shift from home deliveries to hospital deliveries took place during the 1970s, with the result that more than $99 \%$ of the state's deliveries have been taking place in the Women's Hospital. Therefore, the maternal, neonatal, and perinatal data generated by the Women's Hospital, for all practical purposes, represents Qatar's national data. Currently, the maternity unit at the Women's Hospital performs more than 15,000 deliveries per year. The neonatal unit in the Women's Hospital has a total of 80 neonatal beds with 34 intensive care beds. It is well equipped with all kinds of modern neonatal intensive care equipment.

For this study, we collected neonatal and perinatal survival data from the admissions, discharge, and death registers of the Neonatal Intensive Care Unit at the Women's Hospital. Comparative neonatal and perinatal data were also collected from the national database in the Department of Preventive Medicine which records all deaths through death certificates. Maternal mortality data were collected from the annual reports published on behalf of the Ministry of Health (National Health Authority), by the Department of Statistics and Epidemiology at Hamad Medical Corporation. ${ }^{29}$

The parallel, temporally correlated socioeconomic development data was ascertained from the 1981-2008 annual reports of the Qatar Statistics Authority. After its establishment in the late 1970s, the authority published its first report in 1981, which included data for the preceding years as far back as the early 1970s. The 1981-2008 annual reports of the Qatar Statistics Authority are available online on its website (www. qsa.gov.qa) and on an official compact disc provided free of cost by the authority. We also ascertained socioeconomic and health care development data from the annual reports prepared by the Department of Medical Statistics and Epidemiology at Hamad Medical Corporation. ${ }^{29}$

Maternal mortality rate was defined as the number of maternal deaths in a given period per 100,000 live births during the same time period. Neonatal mortality rate was defined as the number of neonatal deaths from 0-28 days of age per 1000 live births. Perinatal mortality rate was defined as the sum of late fetal deaths ( $\geq 24$ weeks) plus early neonatal deaths ( $0-7$ days) divided by the sum of live births and late fetal deaths per 1000 live births and late fetal deaths. Due to their very small and statistically insignificant number, home deliveries, any possible home deaths, very late neonatal deaths ( $>28$ days postnatal age), and babies dying after discharge from the hospital were not included in the study. However, babies born with lethal congenital anomalies, very low Apgar scores, extremely premature (24-28 weeks' gestation), and extremely low birth weight (500-1000 g at birth) who had signs of life at birth but were declared nonviable by the attending clinician and died in the labor room, were included in the neonatal mortality data. Table 1 shows the trend in total births, as well as neonatal and perinatal mortality rates, for Qatar in 1974-2008. 
Table I Trends in neonatal perinatal mortality in Qatar 1974-2008

\begin{tabular}{llllllll}
\hline Year & Births & NM & NMR & ENMR & LNMR & PM & PMR \\
\hline 1974 & 3655 & 96 & 26.27 & 20.25 & 6.02 & 165 & 44.4 \\
1976 & 5061 & 62 & 12.25 & 9.68 & 2.57 & 106 & 20.7 \\
1983 & 8072 & 77 & 9.54 & 5.58 & 3.96 & 124 & 15.2 \\
1992 & 10232 & 85 & 8.31 & 5.08 & 3.23 & 142 & 13.8
\end{tabular}

Era A NMR, $P<0.00$ I; PMR, $P<0.00$ I; ENMR, $P<0.00$ I; LNMR, $P<0.001$.

$\begin{array}{llllllll}1995 & 9995 & 74 & 7.4 & 3.3 & 4.1 & 130 & 12.8 \\ 1999 & 10699 & 132 & 12.34 & 4.3 & 8.04 & 142 & 13.15 \\ 2001 & 11875 & 108 & 9.09 & 4.35 & 4.74 & 140 & 11.7 \\ 2006 & 13741 & 60 & 4.37 & 1.89 & 2.48 & 136 & 9.82 \\ 2007 & 14108 & 72 & 5.1 & 2.34 & 2.76 & 146 & 10.27 \\ 2008 & 14899 & 64 & 4.4 & 2.5 & 1.8 & 159 & 10.58\end{array}$

Era B NMR, $P<0.00$ I; PMR, $P<0.00$ I; ENMR, $P<0.00$ I;

LNMR, $P<0.001$.

Notes: Cumulative analysis 1974-2008: NMR, $P<0.001$; PMR, $P<0.00$ I; ENMR, $P<0.00$ I; LNMR, $P<0.01$.

Abbreviations: NMR, neonatal mortality rate; PMR, perinatal mortality rate; ENMR, early neonatal mortality rate; LNMR, late neonatal mortality rate.

Figure 1 shows biennial neonatal, early neonatal, late neonatal, and perinatal mortality rates for 1974-2008.

To analyze the impact of health care investment on survival rates, we divided the evolution of neonatal perinatal care in Qatar into two distinct temporal eras, ie, era A (1974-1993) and era B (1994-2008).

Era A (1974-2008) started with the establishment of a special care baby unit using low-cost neonatal care with an emphasis on resuscitation at birth, management of hypothermia, prevention and management of sepsis, cardiorespiratory support, better care of low birth weight babies, nutritional management, and promotion of breast feeding. From 1981 onwards, neonatal ventilation and monitoring equipment were gradually introduced into our unit. The limit of viability in this era was 28 completed weeks of gestation.
Era B (1994-2008) was the era of formal neonatal intensive care, including care of extremely low birth weight babies $(<1000 \mathrm{~g})$ and extremely premature $(<28$ weeks' gestation) babies, which necessitated the establishment of a very modern, high-technology, dedicated tertiary care neonatal intensive care unit facility with its own dedicated middle-grade staff. Surfactant replacement therapy was started during the early 1990s. Assisted reproductive technology was introduced in Qatar during the later part of the 1990s, resulting in an increasing number of multiple and extremely premature babies. The limit of viability during this era was gradually lowered to 24 weeks. Exclusive tertiary care neonatal consultants were appointed in the early 2000s.

We studied the patterns of neonatal survival rates and parallel development of socioeconomic indicators, including reduction in poverty, improvement in the standard of living, provision of safe clean drinking water, sanitation, universal access to health care, maternal and child health care, female literacy rate, level of female education, and overall cost of health care. Because direct costs of neonatal care were not available before 1997, we used per capita health care expenditure as a surrogate indicator.

Table 2 shows the pattern of socioeconomic development and maternal and child health indicators in Qatar for 1980-2008. Table 3 shows literacy rates (15 years and above) and female to male literacy ratio during the early reproductive years (15-24 years age). The Chi-square test was used to calculate the statistical significance for drop in the mortality rates. A level of $P<0.05$ was considered as the cutoff value for statistical significance.

Table 2 Socioeconomic development and status of maternal and child health in Qatar from 1980 to $2008^{10,11,19,20,29,44}$

\begin{tabular}{|c|c|c|c|c|c|}
\hline & 1980 & 1986 & 1993 & 2000 & $2007-2008$ \\
\hline Population (millions) & 0.24 & 0.369079 & 0.464236 & 0.682434 & 1.226210 \\
\hline GDP per capita (QAR) & 169,134 & 131,673 & 132,809 & 201,585 & 313,078 \\
\hline GDP per capita (US\$) & 46,464 & 36,173 & 31,485 & 55,378 & 86,008 \\
\hline Health expenditure per capita (QAR) & NA & 1560 & 1850 & 2004 & 4383 \\
\hline Total government budget for health (\%) & $6.3 \%$ & $7.7 \%$ & $7.0 \%$ & $7.0 \%$ & $14.9 \%$ \\
\hline Pregnancies attended by TBA (\%) & $100 \%$ & $100 \%$ & $100 \%$ & $100 \%$ & $100 \%$ \\
\hline Deliveries attended by TBA (\%) & $100 \%$ & $100 \%$ & $100 \%$ & $100 \%$ & $100 \%$ \\
\hline Babies seen by trained person (\%) & $100 \%$ & $100 \%$ & $100 \%$ & $100 \%$ & $100 \%$ \\
\hline Childhood immunization & $80 \%$ & $96 \%-100 \%$ & $96 \%-100 \%$ & $96 \%-100 \%$ & $97 \%-100 \%$ \\
\hline Cases of neonatal tetanus & 3 & I & 0 & 0 & 0 \\
\hline MMR & NA & NA & 0 & 0 & 11.6 \\
\hline$<5 \mathrm{MR}$ & 27.5 & 15.9 & 14.5 & 12.8 & 9.5 \\
\hline IMR & 52 & 21 & 12.5 & 11.7 & 7.7 \\
\hline
\end{tabular}

Abbreviations: NA, authentic data not available; TBA, trained birth attendant; MMR, maternal mortality ratio; MR, mortality ratio; IMR, infant mortality ratio. 
Table 3 Trends in literacy rate in Qatar 1986-2007

\begin{tabular}{llll}
\hline Year & $\begin{array}{l}\text { Literacy rate (\%) } \\
\text { I5 years and older }\end{array}$ & $\begin{array}{l}\text { Literacy rate (\%) } \\
\text { I5-24 years }\end{array}$ & $\begin{array}{l}\text { Female:Male } \\
\text { literacy ratio } \\
\text { I 5-24 years }\end{array}$ \\
\hline 1986 & $77.6 *$ & NA & $97 \%$ \\
1990 & 79.4 & $96.5 \%$ & $96.5 \%$ \\
1995 & NA & $97.3 \%$ & $97.6 \%$ \\
2000 & 87.7 & $98.0 \%$ & $98.5 \%$ \\
2005 & 90.6 & $98.9 \%$ & $99.2 \%$ \\
2006 & 90.8 & $99.0 \%$ & $99.3 \%$ \\
2007 & 93.1 & $99.1 \%$ & $99.9 \%$ \\
\hline
\end{tabular}

Notes: Compiled from data contained in references 19 and 29 from the year 1986 onwards, and literacy rate covers all persons 10 years and above. Abbreviation: NA, authentic data not available.

\section{Results}

During 2008, Qatar's neonatal mortality rate was 4.4/1000 and the perinatal mortality rate was $10.58 / 1000$. The cumulative analysis of 35-year (1974-2008) data has shown a significant reduction $(P<0.0001)$ in neonatal and perinatal mortality rates. During era $A$, the neonatal mortality rate dropped from $26.27 / 1000$ in 1974 to $8.31 / 1000$ in $1992(P<0.001)$. The drop was very dramatic (from $26.27 / 1000$ to $12.25 / 1000$ ) during the first three years (1974-1976). The neonatal mortality rate remained around 12/1000 until 1981 when neonatal ventilation was introduced, which dropped the neonatal mortality rate to $8.8 / 1000$ by 1984 . However, there was no further improvement in the neonatal mortality rate till 1993. The drop in neonatal mortality rate during era A correlates with a drop in early neonatal mortality rate which was reduced by two thirds during the first three years alone (1974-1976) followed by another $50 \%$ by 1983 . During the rest of era A (1984-1993) there was a minimal drop in early neonatal mortality rate. The late neonatal mortality rate dropped by $50 \%$ from 1974 to 1992 .

During era $\mathrm{B}$, the neonatal mortality rate increased from $7.6 / 1000$ in 1994 to $12.1 / 1000$ in 2000 , which was mainly due to the increase in late neonatal mortality rate (from 2.33/1000 in 1994 to 7.5/1000 in 2000). From 2001 onwards, the neonatal mortality rate steadily dropped to $4.4 / 1000$ in 2008 , with a significant drop in late neonatal mortality rate from $7.5 / 1000$ in 2000 to $1.8 / 1000$ in 2008 . The early neonatal mortality rate dropped steadily from 5.5/1000 in 1994 to $2.5 / 1000$ in 2008 , without any peak in the middle years of era B. The mortality rates have almost plateaued since 2005. There was no association between the mortality rates and total annual births, which increased by five-fold during the study period.

Comparative analysis of neonatal survival and parallel improvement in socioeconomic indicators revealed that the per capita health expenditure (Table 2) increased by $19 \%$ during the last seven years of era A (1986-1993), and increased by $137 \%$ during era B (1993 and 2007). For the period 1974-1985 we could not get reliable figures for per capita health expenditure. By the late 1970s and early 1980s Qatar had achieved a significant improvement in its socioeconomic determinants of neonatal survival, including excellence in maternal and child health care (Table 2), rapidly increasing female literacy rates, and female:male literacy ratio (Table 3 ). Socioeconomic development and health care investment correlated well with neonatal survival, although more babies survived during 1974-1976 with less economic and technologic input than the rest of era A and era B.

\section{Discussion}

Neonatal and perinatal survival is part of a package in development of human society which is a multifaceted process involving social, economic, cultural, educational, and health care development. Using the State of Qatar as a model, we studied this association to learn lessons which could help other developing countries to improve their neonatal and perinatal indicators. The decline in neonatal, perinatal, and maternal mortality rates in Qatar evolved through distinct temporal stages. During the first three years of era A (1974-1976), there was a dramatic decline in neonatal mortality (from 20.26/1000 to 12/1000) which correlated with the use of very basic low-cost neonatal technology. The period 1974-1976 was the era when newborn care had just started in Qatar. During these years, the first level one nursery was established. Prior to this era, the babies were kept either in the general pediatric ward or the obstetric ward. The newborn nursery provided basic care, including neonatal resuscitation, temperature control using incubators, infection control, fluid balance, breast feeding, and care of low birth weight babies. There were no high technological equipments available at this stage. The main survivors of this period were term and bigger preterm babies. The perinatal mortality rate decreased from 44.4/1000 in 1974 to 20.7/1000 in 1976. From 1976-1993, the neonatal mortality rate showed a slow and steady but significant decline except between 1981-1983, which correlated with the introduction of rather expensive neonatal ventilation technology. The perinatal mortality rate followed the same pattern. Between 1984 and 1992 the drop in neonatal mortality rate was not significant (from $8.8 / 1000$ to $8.3 / 1000$ ), which reflects the fact that further improvement was possible only with the introduction of a high technological and expensive neonatal intensive care 
facility which is out of the reach of developing countries. During era A, neonatal care was provided in a special care baby unit managed by general pediatricians with a special interest in newborn care. We could not get reliable data about the cost of neonatal care between 1974 and 1985. However, the $19 \%$ increase in overall per capita health expenditure during the last seven years of era A (1986-1993) correlates well with the fact that a very significant decline in neonatal, perinatal, and maternal mortality can be achieved with restricted resources, provided that the focus of investment is clear. During era B (1993-2008) Qatar's per capita health expenditure increased by $137 \%$. Neonatal mortality increased during the earlier part of this era (from 7.6/1000 in 1994 to $12 / 1000$ in 2000 ). The main reason was a change in the neonatal unit population (increasing number of $<28$ weeks and $<1000 \mathrm{~g}$ babies) which correlated with the introduction of high-cost technologies (assisted reproduction and intensive neonatal care). The majority of these extremely premature babies survived during the first week of life due to excellent delivery room management followed by intensive neonatal care. However, a significant number of these extremely preterm babies had late neonatal death due to complications of extreme prematurity. Therefore, Qatar had less early neonatal deaths and more late neonatal deaths during this era. Increasing survival was associated with increasing respiratory and neurologic morbidity with ongoing cost of long-term care. From 2001 onwards, the neonatal mortality rate steadily dropped from $9 / 1000$ to $4.4 / 1000$ in 2008 which correlated well with the appointment of dedicated tertiary care neonatologists and more modern equipment in our unit. Qatar's neonatal mortality rate has remained almost static at around $5 / 1000$ live births since 2005 , which is a pattern noted in all developed countries. ${ }^{29,31}$ From 1974-2008, the total number of annual births in Qatar increased by fivefold. However, we did not find any association between neonatal mortality rates and total number of annual births.

Qatar's remarkable achievement of maternal, neonatal, and perinatal survival was not a phenomenon in isolation. It has evolved as a part of the global socioeconomic and cultural changes in society, the most important being the reduction in poverty and increase in female literacy. Extreme poverty has been the world's biggest killer and the greatest cause of ill health and suffering across the globe. ${ }^{32}$ Infant mortality, a very strong outcome indicator of ill health, is most sensitive to poverty. ${ }^{33,34}$ Increased socioeconomic development is associated with a consistent decline in infant mortality. ${ }^{35,36}$ Qatar's oil- and natural gas-based economy has grown exponentially since 1990. The State's gross domestic product per capita, which was US $\$ 46,464$ in 1980, dropped by $32 \%$ to reach $\$ 31,485$ in 1993 , followed by $171 \%$ growth to $\$ 85,370$ in 2007 (Table 2). In 2008, Qatar had the highest gross domestic product per capita in the world $(\$ 86,008) .{ }^{20}$ Poverty, measured by the ratio of those with an income of less than one dollar per day, has long been eliminated in Qatar. ${ }^{19}$ The Household Expenditure and Income Survey 2006/07 has shown that the average individual's expenditure in Qatar is $\$ 33$ per day. ${ }^{19}$ Qatar's standard of living is very high, with abundant clean drinking water, efficient sewage, drainage, pest control, environmental control, public health awareness programs, communication, electricity, and transportation facilities.

Due to heavy investment in the health sector, the quality of health care in Qatar is high, even by Western standards. ${ }^{37}$ The state provides universal access to health care, including maternal and child health care. A shift from home to hospital deliveries took place during the 1970s. Since 1980, Qatar has achieved almost $100 \%$ coverage of its pregnancies and deliveries by trained birth attendants (Table 3). Of the newborn babies, almost $100 \%$ have been seen by a trained person since 1974. The level of childhood immunization, which was $80 \%$ in 1980 , reached $96 \%-100 \%$ by 1986 . The state had only three cases of neonatal tetanus in 1980 and one case in 1986. Since then there has been no recorded case of neonatal tetanus in Qatar. The measles immunization rate in Qatar is at least 93\%, which is a bench mark level for most developed countries. ${ }^{12}$ The maternal mortality rate remained zero in 1993, 1995, and then from 1998-2000. For the rest of the years, maternal mortality rate has been approximately $10 / 100,000 .^{9}$

Many studies over the last two decades have shown that maternal education is a decisive factor in child survival..$^{33,35,38-41}$ This association has been observed in both developing ${ }^{35,38}$ and developed countries. ${ }^{39,41}$ Our study confirms the same correlation in the State of Qatar, which started investing in education back in the 1960s with equal opportunities for men and women. The state has a high rate as well as a high level of female literacy. In 1986, the overall literacy rate (above 10 years) was $77.6 \%$, with a female to male ratio of $97 \%$ (Table 3). By 2007, the overall literacy rate had reached $93.1 \%$, while the literacy rate during childbearing age (15-24 years) was $99.1 \%$, with a female:male ratio of $99.9 \%$. During the school years, the number of boys has remained slightly higher than girls. However, at the university level, the number of girls remained double the number of boys as far back as 1980 (www.qsa.gov.qa). By 2007, there were three girls for every one boy in Qatar University. The very high rates and level of female literacy in Qatar from 1974 to 1993 is temporally well correlated with 
a rapid decline in child (including neonatal), perinatal, and maternal mortality rates. The same pattern has been reported by other GCC countries which have gone through a similar phase of very rapid socioeconomic development. ${ }^{35,40}$

Our review of Qatar's socioeconomic development and its remarkable achievement of neonatal survival over a period of 35 years provides further evidence to perinatal health care policy makers on where and how to invest in neonatal perinatal health care to reduce the burden of four million neonatal and half a million maternal deaths every year worldwide. The issues of maternal, childhood, and neonatal mortality must be addressed at a wider community level. Poverty reduction, increase in the standard of living, supply of clean safe drinking water, efficient sewage and waste disposal, pest control, preventive medicine, and universal access to health care, all supported by a strong undivided political commitment, are essential backdrops of any child survival program. Reproductive health care, female literacy, attendance of all pregnancies, deliveries, and newborn babies by trained personnel, universal childhood immunization, and essential breast feeding practices are major contributory factors to maternal and neonatal survival. The sharp decline in neonatal mortality during 1974-1976 in Qatar supports the view that a large reduction in neonatal deaths can be achieved by phasing out the targets of neonatal survival in developing countries with socioeconomic resource restrictions. Malaysia, during its rapid socioeconomic development, had a similar phasic pattern of neonatal survival. ${ }^{35,36}$ A recent study from Chile $^{42}$ advocates the efficacy of institution-based neonatal care interventions in reducing birth weight and gestational age-specific neonatal mortality. However, the authors of this study ${ }^{42}$ have accepted that success would not have been possible without wider socioeconomic improvement in Chile during the 1990s, which included a progressive increase in per capita income, 50\% reduction in poverty, a significant increase in maternal education, and a three-fold increase in expenditure in the public health sector. Our study substantiates these findings.

Based on our study, we propose that in resource-restricted countries the first stage of improvement in neonatal survival should target babies $>2000$ g at birth and $>32$ weeks' gestation. The majority of these term and bigger preterm babies can be saved by low-cost neonatal technology, with the emphasis on neonatal resuscitation, management of hypothermia, prevention and management of sepsis, promotion of breast feeding, respiratory support with continuous positive airways pressure, and extra care of low birth weight babies. At a global level, this strategy will save millions of newborn babies at a cost affordable even by the poorest of poor countries. The intervention bar can be gradually lowered as progressively better neonatal survival rates are achieved. Sri Lanka has created a very good example for low-income countries by achieving excellent neonatal survival in a resource-restricted environment. ${ }^{43}$ Umbrella organizations, such the WHO, should develop separate criteria for limits of neonatal viability for developing countries, which should essentially exclude fetuses $<28$ weeks gestation and $<1000 \mathrm{~g}$ at birth, and the neonatal population which needs very highcost neonatal intensive care for its survival, and is an area beyond the reach of developing nations.

This study is based on two parallel databases which have temporal correlations. Therefore, direct testing of statistical correlations was not possible. A prospective study involving many regional countries would provide a better understanding of the outcomes and their correlates. The strength of the study is that it is limited to one country in the unique situation of having $99 \%$ of deliveries in a single large maternity and newborn care unit. Therefore, the care provided and the data generated are homogenous.

\section{Acknowledgment}

We are grateful to Mr Abdul Hadi Ali Awad, Statistics Expert, Qatar Statistics Authority, and Mrs Soji Samson, Department of Epidemiology and Medical Statistics, Hamad Medical Corporation, Qatar, for obtaining socioeconomic development data and statistical analysis. We are indebted to Dr Siraj ul Islam Khan, Consultant Neonatologist, Women's Hospital, Qatar (1977-2000) for his permission to use the excellent neonatal database he had built over a period of 23 years.

\section{Disclosure}

The authors report no conflicts of interest in this work.

\section{References}

1. United Nations International Children's Emergency Fund. State of the World's Children 2007. Available at: http://www.unicef.org/sowc07/. Accessed Aug 5, 2010.

2. World Health Organization. The World Health Report. Geneva, Switzerland: World Health Organization; 2005. Available from: http://www.who.int/whr/2005/en/index.html. Accessed Aug 5, 2010.

3. World Health Organization. Neonatal and Perinatal Mortality. Country, Regional and Global Estimates. Geneva, Switzerland: World Health Organization; 2006. Available from: http://whqlibdoc.who.int/ publications/2006/9241563206_eng.pdf. Accessed Aug 5, 2010.

4. Rahman S. Survival of the smallest at the turn of the century. Pak $J$ Pathol. 1996:20;129-135.

5. Martin JA, Hamilton BE, Sutton, PD, et al. Births: Final data for 2006. National Vital Statistics Reports. Hyattsville, MD: National Center for Health Statistics; 2009. Available from: http://www.cdc.gov/nchs/data/ nvsr/nvsr57/nvsr57_07.pdf. Accessed Aug 5, 2010. 
6. Office of National Statistics. Gestation specific infant mortality by social and biological factors, 2006. London, UK: Office of National Statistics; 2009. Available from: http://www.ons.gov.uk. Accessed Jan 15, 2010.

7. Alexander GR, Kogan M, Bader D, et al. US birth weight/gestational age specific mortality: 1995-1997 Rates for Whites, Hispanics and Blacks. Pediatrics. 2003;111:e61-e66.

8. Lawn JE, Cousens S, Zupan J; for the Lancet Neonatal Survival Steering Team. Four million neonatal deaths: When? Where? Why? Lancet. 2005;365:981-900.

9. World Health Organization. The Millennium Development Goals Report 2007. Available from: http://www.who.org. Accessed Jan 15, 2010.

10. Hogan MC, Foreman KJ, Naghavi M, et al. Maternal mortality for 181 countries, 1980-2008: A systematic analysis of progress towards Millennium Development Goal 5. Lancet. 2010;375:1609-1623.

11. Rajaratnam JK, Marcus JR, Flaxman AD. Neonatal, post neonatal, childhood, and under-5 mortality for 187 countries, 1970-2010: A systematic analysis of progress towards Millennium Development Goal 4. Lancet. 2010;375:1988-2008.

12. Regional Health Systems Observatory-EMRO World Health Organization. Health Systems Profile Qatar 2006. Available from: http://www. emro.who.int. Accessed Jan 15, 2010.

13. Regional Health Systems Observatory-EMRO World Health Organization. Health Systems Profile UAE 2006. Available from: http://www. emro.who.int. Accessed Jan 15, 2010

14. Regional Health Systems Observatory-EMRO World Health Organization. Health Systems Profile Saudi Arabia 2006. Available from: http:// www.emro.who.int. Accessed Jan 15, 2010.

15. Regional Health Systems Observatory-EMRO World Health Organization. Health Systems Profile Bahrain 2007. Available from: http://www. emro.who.int. Accessed Jan 15, 2010.

16. Regional Health Systems Observatory-EMRO World Health Organization. Health Systems Profile Kuwait 2007. Available from: http://www. emro.who.int. Accessed Jan 15, 2010.

17. Mourshed M, Hediger V, Lambert T. Gulf Cooperation Council Health Care. Challenges and Opportunities. Available from: http://www.weforum.org/pdf/Global_Competitiveness_Reports/.../2_1.pdf. Accessed Jan 17, 2010.

18. Boutayeb A, Serghini M. Health indicators and human development in the Arab region. Int J Health Geogr. 2006;5:61.

19. Qatar Statistics Authority. The Millennium Development Goals in the State of Qatar. 2008. Available from: (http://www.qsa.gov.qa). Accessed Mar 8, 2010.

20. Index Mundi. Qatar GDP - per capita (PPP). Equivalent data from the International Monetary Fund. Available from: http://www.indexmundi. com/qatar/gdp_per_capita_(ppp).html. Accessed Jul 30, 2010.

21. General Secretariat for Development Planning. Qatar National Vision 2030. Available from: http://www.planning.gov.qa. Accessed Jul 30, 2010.

22. Qatar Earth Trends. Population, Health, and Human Well Being 2003. Available from: http://earthtrends.wri.org. Accessed Mar 8, 2010.

23. Qatar Regional Health Systems Observatory-EMRO Annual Report 2003 Health Systems Profile. Available from: http://www.emro.who. int. Accessed Jan 15, 2010.

24. Salameh K, Rahman S, Al Rifai H, et al. An analytic study of trends in perinatal and neonatal mortality rates in the State of Qatar over a 30 year period (1977-2007): A comparative study with regional and developed countries. J Perinatol. 2009;29:765-770.
25. Mangiaterra V, Mattero M, Dunkelberg E. Why and how to invest in neonatal health. Semin Fet Neonatal Med. 2006;11:37-47.

26. Darmstadt GL, Bhutta ZA, Cousens S, Adam T, Walker N, de Bernis L; Lancet Neonatal Survival Steering Team. Evidence based, cost effective interventions: How many newborn babies can we save? Lancet. 2005;365:977-988.

27. Jones G, Steketee RW, Black RE, Bhutta ZA, Morris SS; Bellagio Child Survival Study Group. How many child deaths can we prevent this year? Lancet. 2003;362:65-71.

28. Uxa F, Bacci A, Mangiaterra V, Chiaffoni GP. Essential newborn care training activities: 8 years of experience in Eastern Europe, Caucasian and Central Asian Countries. Semin Fet Neonatal Med. 2006; 11:58-64.

29. Hamad Medical Corporation. Annual Health Report 2009. Qatar: Hamad Medical Corporation; 2010. Available from: http:/www.hmc.org.qa. Accessed Aug 5, 2010.

30. Horbar JD, Badger GJ, Carpenter JH, et al. Trends in mortality and morbidity for very low birth weight infants, 1991-1999. Pediatrics. 2002;110:143-151.

31. Meadow W, Lee G, Lin K, Lantos J. Changes in mortality for extremely low birth weight infants in the 1990s: Implications for treatment decisions and resource use. Pediatrics. 2004;113:1223-1229.

32. Kevany J. Extreme poverty: An obligation ignored. BMJ. 1996; 313: 65-66.

33. Jahan S. Poverty and infant mortality in the Eastern Mediterranean region: A meta-analysis. J Epidemiol Community Health. 2008;62:745-751

34. Al-Hosani HA, Brebner J, Bener AB, Norman JN. Study of mortality risk factors for children under age 5 in Abu Dhabi. East Mediterr Health J. 2003;9:333-343.

35. DaVanzo J. Infant mortality and socioeconomic development: Evidence from Malaysian household data. Demography. 1988;25:581-595.

36. Peng TN, Ann TB, Arshat H. Multivariate areal analyses of neonatal mortality in peninsular Malaysia. Malays J Reprod Health. 1985;3: 46-58.

37. Qatar Regional Health Systems Observatory- EMRO Annual Report. Health Systems Profile 2003. Available from: http://www.emro.who. int. Accessed Jan 15, 2010

38. Ramji S. The National Family Health Survey (1998-1999): Childhood mortality. Indian Pediatr. 2001;38:263-266.

39. Arntzen A, Mortensen L, Schnor O, et al. Neonatal and postneonatal mortality by education - a population based study of trends in the Nordic countries, 1981-2000. Eur J Public Health. 2008;18:245-251.

40. Shah NM, Shah MA. Socioeconomic and health care determinants of child survival in Kuwait. J Bio Med Sci. 1990;22:239-253.

41. Bicego GT, Boerma JT. Maternal education and child survival: A comparative study of survey data from 17 countries. Soc Sci Med. 1993;36: 1207-1227.

42. Gonzelez R, Merialdi M, Lincetto O, et al. Reduction in neonatal mortality in Chile between 1990 and 2000. Pediatrics. 2006;117: e949-e954.

43. de Silva DGH. Perinatal care in Sri Lanka: Secrets of success in low income country. Semin Neonatol. 1999;4:201-207.

44. Qatar Statistics Authority. 2008. Available from: Accessed Jul 10, 2010.
International Journal of Women's Health

\section{Publish your work in this journal}

The International Journal of Women's Health is an international, peerreviewed open-access journal publishing original research, reports, reviews and commentaries on all aspects of women's healthcare including gynecology, obstetrics, and breast cancer. Subject areas include: Chronic conditions (migraine headaches, arthritis, osteoporosis);
Endocrine and autoimmune syndromes; Sexual and reproductive health; Psychological and psychosocial conditions. The manuscript management system is completely online and includes a very quick and fair peer-review system. Visit http://www.dovepress.com/ testimonials.php to read real quotes from published authors. 